\title{
Mindfulness therapy in patients with chronic tension-type headaches
}

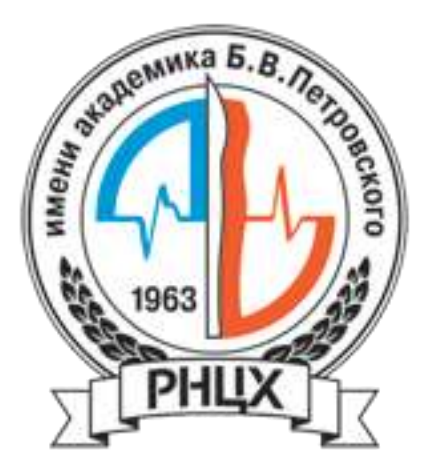

\author{
G. Shevtsova' ${ }^{1}$, Y. Malenkova ${ }^{2}$, O. Zagorulko², L. Medvedeva ${ }^{2}$ \\ ${ }^{1}$ First Moscow State Medical University \\ ${ }^{2}$ National Research Centre of Surgery \\ Moscow, Russia
}

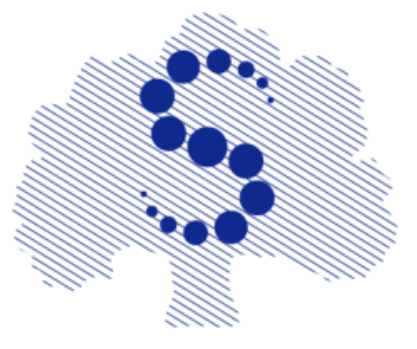

SECHENOV UNIVERSITY

Background and Goal of Study: Chronic tension-type headache $(\mathrm{CTTH})$ is the most prevalent headache disorder in the general population, ranging from $20 \%$ to $60 \%[1,2]$.

Materials and Methods: The study, approved by the Institutional Review Board, was double blinded placebo controlled and involved 58 amateur athletes with CTTH. The diagnose met International Classification of Headache Disorders criteria. Patients, who attended the clinic in Sept.2016Aug.2017, were divided into two groups (29 patients each) by the sealed envelope method. Both groups received venlafaxitine 75 $\mathrm{mg} /$ day and tizanidine $4 \mathrm{mg} /$ day during 12 and 4 weeks respectively, control group additionally was educated with mindfulness meditation techniques (weekly 2-hour group sessions with following daily outside preparation and individual session for every participant). The treatment effectiveness was evaluated prior to and 12 weeks after the treatment by pain attacks frequency and severity with the Visual Analog Scale (VAS) and Pain Catastrophizing Scale (PCS).

Results and Discussion: The mean age was $38.5 \pm 9.1$ and $51.5 \pm 8.4$ in the study and control group, respectively. Most of respondents were females (32 and 26). The pretreatment VAS score was $6.2 \pm 1.1$ and $5.9 \pm 1.5$ points and pain attack frequency - 19.2 \pm 5.4 and 22.1 \pm 7.2 per month, total PCS score $-21.1 \pm 9.1$ and $19.4 \pm 8.7$ points in the study and control groups, respectively. After the 3-months treatment, VAS score was significantly lower in the study group $(1.1 \pm 0.3)$ than in control group (2.5 $\pm 0.8 ; p<0.05)$, as well as total PCS score $(10.2 \pm 8.1$; $16.3 \pm 10.6$ respectively, $p<0.05)$.

Conclusion(s): Mindfulness therapy can significantly improve pain states in CTTH patients.

\section{References:}

1. Zagorulko O. Europ J Anaesth 2016;33(S54):356.

2. Osipova V. Cephalalgia.2016;36(S1):72.

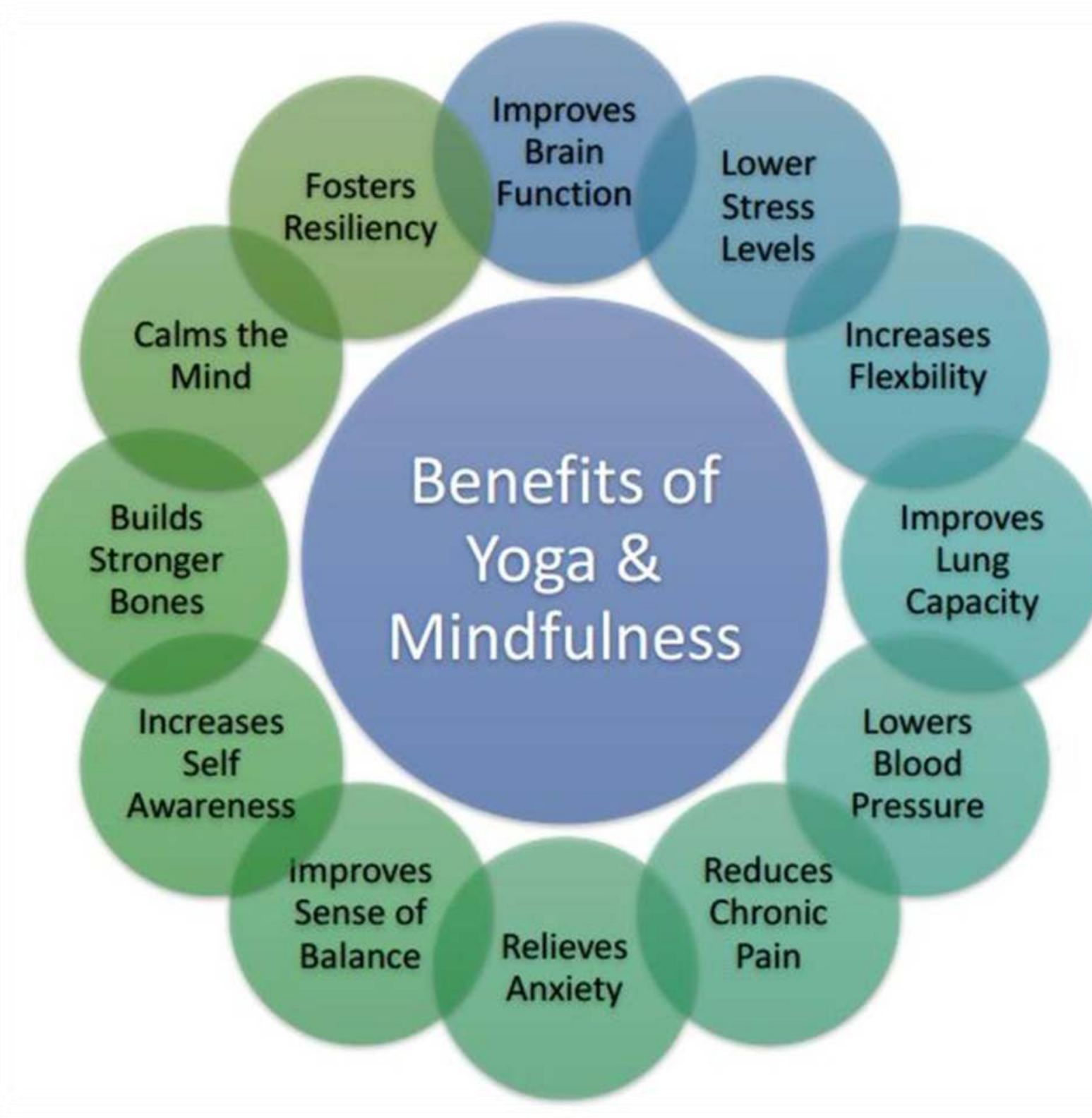

Pain intensity dynamics during treatment by VAS

\begin{tabular}{|l|c|c|}
\hline & $\begin{array}{c}\text { Study group, } \\
\text { points }\end{array}$ & $\begin{array}{c}\text { Control group, } \\
\text { points }\end{array}$ \\
\hline Pretreatment & $6.2 \pm 1.1$ & $5.9 \pm 1.5$ \\
\hline $\begin{array}{l}\text { After 3-month } \\
\text { treatment }\end{array}$ & $1.1 \pm 0.3$ & $2.5 \pm 0.8$ \\
\hline
\end{tabular}

Total PCS score dynamics during treatment

\begin{tabular}{|l|c|c|}
\hline & $\begin{array}{c}\text { Study group, } \\
\text { points }\end{array}$ & $\begin{array}{c}\text { Control group, } \\
\text { points }\end{array}$ \\
\hline Pretreatment & $19,4 \pm 8,7$ & $21,1 \pm 9,1$ \\
\hline $\begin{array}{l}\text { After 3-month } \\
\text { treatment }\end{array}$ & $16,3 \pm 10,6$ & $10,2 \pm 8,1$ \\
\hline
\end{tabular}

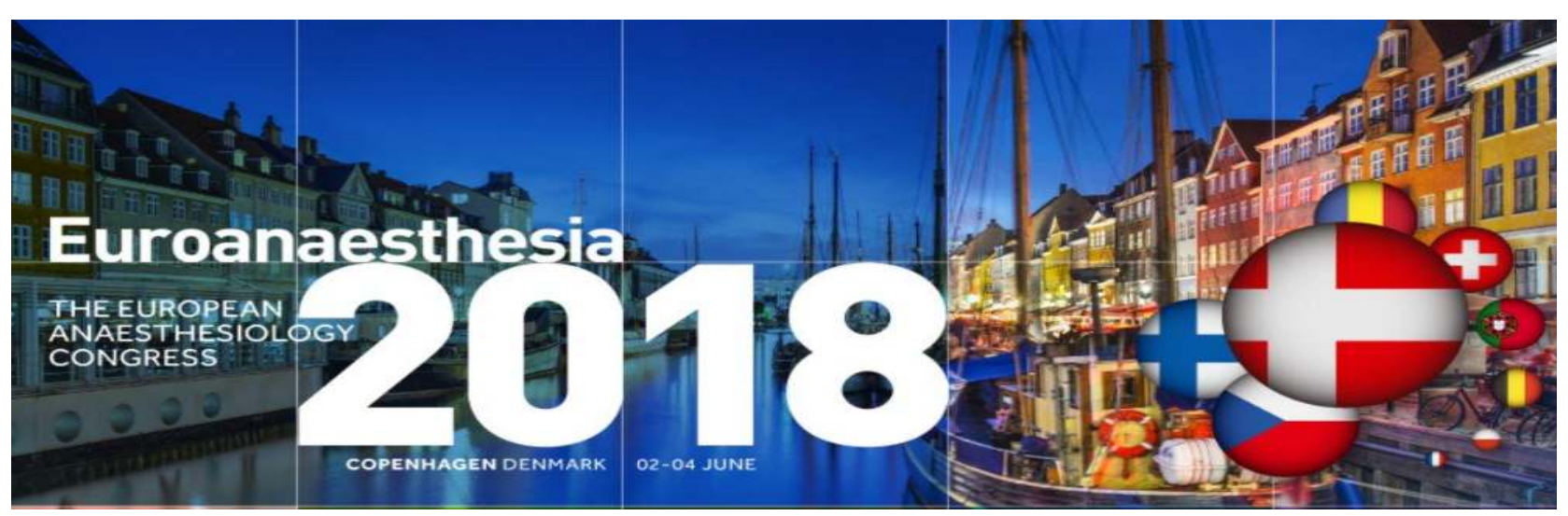

